\title{
AN ANALYSIS OF SOME PILOT FERTILIZER EXPERIMENTS ON PADDY
}

\author{
C. T. DE WIT \\ Formerly: Adviser Soil Research, Agricultural Research Institute, Rangoon, \\ Union of Burma. \\ At present: Institute for Biological and Chemical Research on Field Crops, \\ Wageningen, Holland.

\section{SUMMARY} \\ The average results of 25 pilot fertilizer experiments on paddy in the Union of Burma \\ are discussed. It is claimed that a treatment on basis of the relations between fertilizer \\ rate and uptake, and uptake and yield gives, as far as the experiments go, the most detailed \\ information on the effect of nitrogen and phosphate on the yield.
}

\section{INTRODUCTION}

It was shown in another paper (DE WIT, 1953) that, treating fertilizer experiments, it is worthwhile to consider the relation between fertilizer rate and uptake of the applied minerals and the relation between this uptake and yield.

This latter relation is in many cases independent of the kind of fertilizer, and time and pattern of application. On the other hand, it is in certain cases possible to estimate the effect of the above mentioned factors on the relation between fertilizer rate and uptake.

It is often necessary to carry out fertilizer experiments of a simple design in order to obtain some basis for further work. As for paddy (Oryza sativa L.), a suitable experimental design was worked out by the First Working Party on Fertilizers of the International Rice Commission.

On basis of the results of experiments, carried out according this design, it will be shown here, that it is worthwhile to determine the mineral contents of the yield products and to analyse such simple pilot experiments as proposed in the above mentioned paper.

\section{THE EXPERIMENTS}

During the season 1954-1955, in the Pegu District of the Union of Burma about eighty fertilizer experiments on paddy were carried out by KosHaL and Maung Maung KHIN (1955), respectively a FAO statistician and the statistician of the Department of Agriculture. They showed that yield responses to nitrogen and phosphate fertilizer were significant.

The results of a chemical analysis of the yield products of 25 experiments, carried out at the Agricultural Research Institute in Rangoon and a more detailed interpretation than can be given in this paper, may be found in a report of DE WIT and KHIN WIN (1955).

The Pegu District is found in the Sittang Valley in the South of Burma. The experiments were done during the rainy season from June to November on alluvial soils, flooded with rain water. This soil contained about 5-15\% clay, $10-30 \%$ silt and $0.5-1.5 \%$ organic matter. The $\mathrm{pH}$-water of dried samples ranged from 5.0-7.5 units and available phosphorus was according to several standards low. 
The treatments were no fertilizer, $\mathrm{N}_{1}, \mathrm{~N}_{2}, \mathrm{P}, \mathrm{PN}_{1}$ and $\mathrm{PN}_{2}$ with $\mathrm{N}_{1}=$ $22.4 \mathrm{~kg} \mathrm{~N} / \mathrm{ha}, \mathrm{N}_{2}=44.8 \mathrm{~kg} \mathrm{~N} / \mathrm{ha}$ as ammonium sulphate, and $\mathrm{P}=33.6 \mathrm{~kg}$ $\mathrm{P}_{2} \mathrm{O}_{5} /$ ha as super phosphate.

Experimental fields were selected at random and one block (no repetition) was laid out on each field. The fertilizer was broadcast, as far as possible on drained fields, and tried to work in by means of a Burmese blade harrow. This is an ox-drawn implement which works weeds into the mud, but does not mix the toplayer.

The average results of 25 experiments are given in table 1 .

Table 1 Average results of 25 experiments, all values in $\mathrm{kg} / \mathrm{ha}$.

\begin{tabular}{c|c|c|c|c|c|c|c}
\hline \multicolumn{2}{c}{ Treatment } & \multicolumn{2}{c|}{ Yield } & \multicolumn{2}{c|}{$\mathrm{P}_{2} \mathrm{O}_{5}$} & uptake & \multicolumn{2}{c}{ N uptake } \\
\cline { 3 - 7 } $\mathrm{P}_{2} \mathrm{O}_{5}$ & $\mathrm{~N}$ & paddy & straw & paddy & straw & paddy & straw \\
\hline & & & & & & & \\
0 & 0 & 1740 & 2801 & 7.8 & 4.1 & 16.4 & 10.1 \\
0 & 22.4 & 1873 & 3117 & 9.1 & 4.0 & 17.6 & 10.7 \\
0 & 44.8 & 2146 & 3423 & 9.7 & 4.7 & 20.4 & 12.5 \\
33.6 & 0 & 1838 & 2888 & 9.3 & 4.4 & 16.9 & 9.3 \\
33.6 & 22.4 & 2164 & 3451 & 11.5 & 5.6 & 20.2 & 11.5 \\
33.6 & 44.8 & 2157 & 3764 & 11.5 & 5.9 & 20.2 & 13.5 \\
\hline
\end{tabular}

The straw yields are exclusive stubble and some minerals may be lost from straw because of leaching and loss of leaves. The uptake of a mineral is calculated by multiplying paddy and straw yields of each experiment with their content of this mineral and averaging these uptakes.

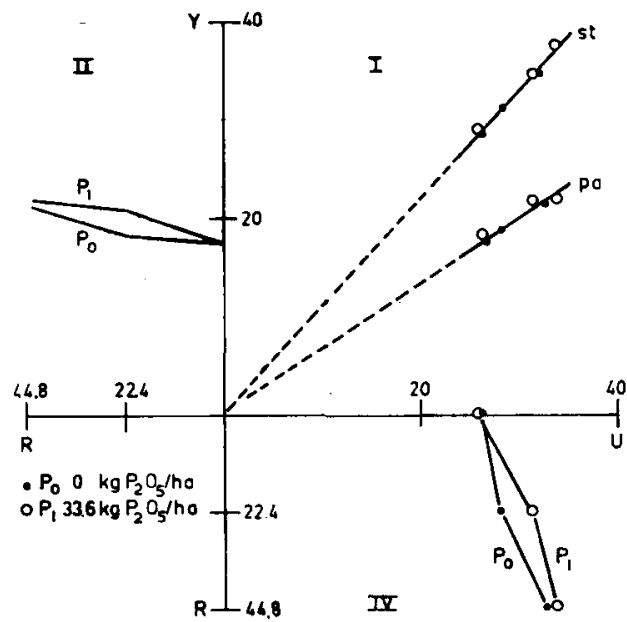

Fig. la The Relation between fertilizer RATE AND UPTAKE (QUADRANT IV), UPTAKE AND YIELD (QUADRANT I) AND FERTILIZER RATE AND YIELD (QUADRANT II) FOR NITHOGEN AT TWO PHOSPHATE LEVELS.

$\mathrm{R}$ : fertilizer rate in $\mathrm{kg} \mathrm{N} / \mathrm{ha} ; \mathrm{U}$ : uptake in paddy plus straw in $\mathrm{kg}$ $\mathrm{N} / \mathrm{ha} ; \mathrm{Y}$ : yield of paddy (pa) and yield of straw (st) in 100 $\mathrm{kg} / \mathrm{ha}$.

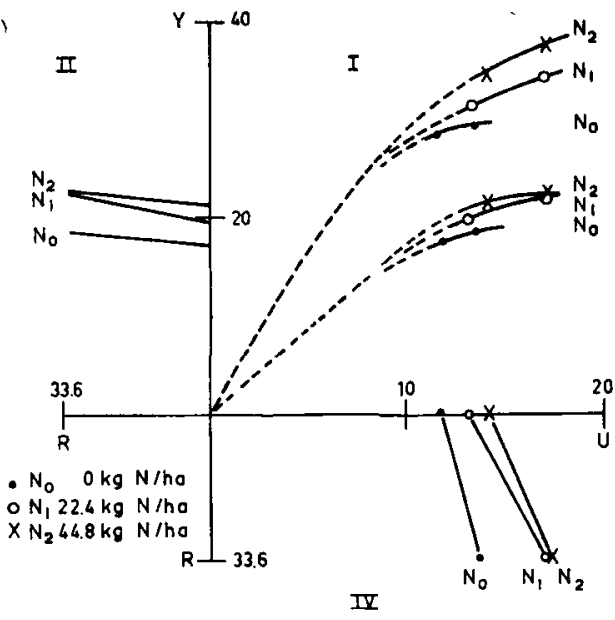

Fig. Ib The same for phosphate at three NITROGEN LEVELS.

$\mathrm{R}$ : fertilizer rate in $\mathrm{kg} \mathrm{P}_{2} \mathrm{O}_{5} / \mathrm{ha}$; $\mathrm{U}$ : uptake in paddy plus straw in $\mathrm{kg} \mathrm{P}_{2} \mathrm{O}_{5} / \mathrm{ha} ; \mathrm{Y}$ : yield of paddy and straw in $100 \mathrm{~kg} / \mathrm{ha}$. 


\section{A gRAPHiCAL REPRESENTATION OF THE RESUlts}

The data are summarized in figure 1. Figure la refers to nitrogen $(\mathbf{N})$ and figure $1 \mathrm{~b}$ to phosphate $\left(\mathrm{P}_{2} \mathrm{O}_{5}\right)$ uptake. In quadrant IV of each figure the relations between fertilizer rate and uptake (the rate-uptake curves) are given and in quadrant I of each figure the relations between uptake and paddy, respectively straw yield (the uptake-yield curves). The relation between fertilizer rate and yield, for paddy only, (the rate-yield curve) was calculated from the curves in quadrant I and IV and is represented in quadrant II.

The uptake-yield curve for nitrogen is independent of the phosphate treatment and is a straight line through the origin. The uptake-yield curve for phosphorus depends, however, on the nitrogen treatment and is not a straight line through the origin. The dotted parts of the curves are arbitrary, but in spite of this given, to stress that at zero yield, uptake is also zero. The form of the curves agrees with many other uptake-yield curves given by DE WIT (op. cit.).

The rate-uptake curves for nitrogen do not coincide and are not parallel. At an application of $22.4 \mathrm{~kg} \mathrm{~N} / \mathrm{ha}$, the nitrogen uptake is in the absence of phosphate low, compared with the uptake in presence of phosphate, which is not the case at an application of $44.8 \mathrm{~kg} \mathrm{~N} / \mathrm{ha}$. Similar discrepancies are shown by the rate-uptake curves for phosphate. As interactions of this kind are difficult to apply in advisory work, hard to explain and in this case anyhow small, it is justified to ignore these and to represent the rate-uptake curves for nitrogen by two and for phosphate by three parallel curves.

These parallel curves are given in the quadrants IV of figure $2 \mathrm{a}$ and $2 \mathrm{~b}$. These figures hold, therefore, under the supposition that there is no interaction between the effect of the phosphate and nitrogen treatments on the uptake of these minerals. The uptake-yield curve for nitrogen in figure $2 \mathrm{a}$ is kept the same as in figure la. The uptake-yield curves for phosphate must than be redrawn, however, in such a way that yields read in quadrant II of figure

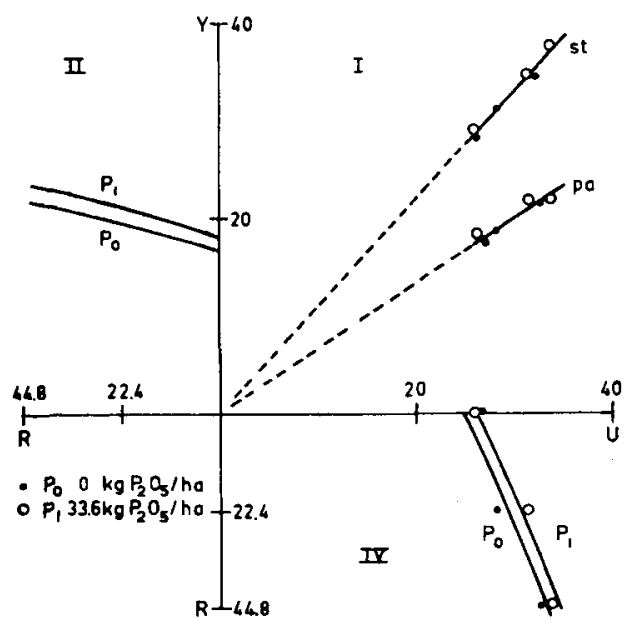

Fig. 2a For NITROGEN.

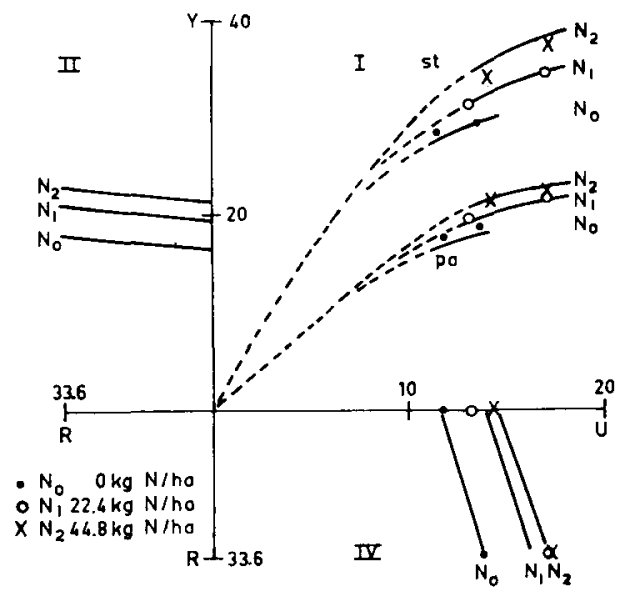

Fig. 2b For phosphate.

Fig. 2 The SAME as FIGURE 1, BUT FOR THE SUPPosition THAT THERE IS No INTERACTION BETWEEN THE EFFECTS OF THE PHOSPHATE AND NITROGEN TREATMENTS ON THE UPTAKE OF 'THESE MINERALS. 
$2 \mathrm{~b}$ are the same as those in quadrant II of figure $2 \mathrm{a}$, for the same combinations of nitrogen and phosphate. Therefore, the uptake-yield curves for phosphate do not fit the observational points in the best possible way. It appears that the full drawn parts of these curves are parallel. This is in this case a consequence of the supposition that the curves in quadrant IV are parallel.

The difference between the uptake by plants on fertilized and unfertilized plots is called, not quite correctly, the uptake from fertilizer. The recovery is defined as this uptake divided by the applied amount of the mineral and ranges from 0 to 1 .

\section{Discussion}

In figure $2 \mathrm{a}$ it may be read that the recovery of nitrogen is about 0.18 (quadrant IV) and that about $65 \mathrm{~kg}$ of paddy is obtained for each $\mathrm{kg}$ of nitrogen taken up from fertilizer (quadrant $\mathrm{I}$ ). The yield response is therefore $0.18 \times 65=11.7 \mathrm{~kg}$ of paddy for each $\mathrm{kg}$ of nitrogen applied (quadrant II). The value of $65 \mathrm{~kg}$ of paddy and the straight line relationship between uptake and yield indicate that nitrogen is deficient and that the utilization of nitrogen, once taken up, is very good. The recovery of 0.18 is, however, at least for nitrogen, low and the yield response should be higher if way and means could be found to increase this recovery.

Superficial application of ammonium on drained, wet paddy fields results in nitrification, followed after flooding by leaching and denitrification (DE Geus, 1954). Moreover, it was shown by DE WIT (op. cit.) that, where recovery of broadcast nitrogen is low, it is possible to improve this value by placing the fertilizers in rows. An estimate based on this paper is, that in case of placement of around $20 \mathrm{~kg} \mathrm{~N} / \mathrm{ha}$ in rows below the aerobic mud layer, the recovery should be at least doubled.

As ( $\mathrm{DE}_{\mathrm{E}} \mathrm{W}_{\mathrm{IT}}$, op. cit.) the relation between uptake and yield ${ }^{1}$ ) is not affect-

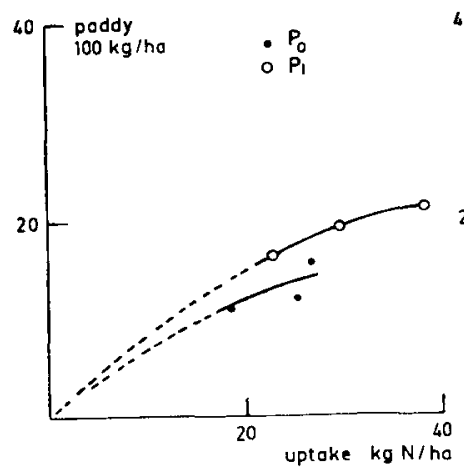

Fig. 3 The UPTAKe-Yield CURVE FOR NITROGEN on kwin No. 1168 IN PEgU TOWNSHIP.

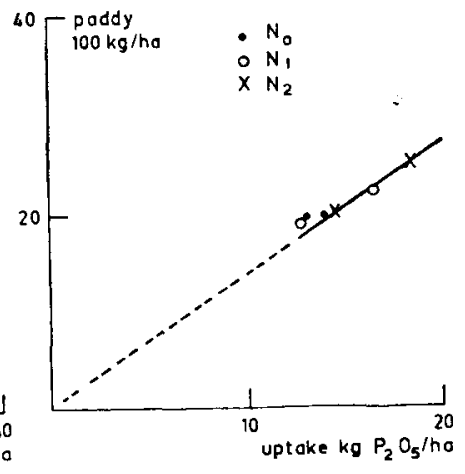

Fig. 4 The UPTaKe-YIeld CURVE For PhosPHATE on kwin No. $815 \mathrm{~B}$ IN WaW TOWNSHIP.

1) The place where a certain quantity of nutrient is taken up does not influence the use thereof by the plant. If, however, application of the fertilizer affects the availability of another nutrent in the soil, the relation between uptake and yield may depend on the method of placement. This is in general the case with potash fertilizers (antagonistic effects on the uptake of other cations). 
ed by the application pattern, the yield response in case of deep placement should be about $0.36 \times 65=23 \mathrm{~kg}$ of paddy for each $\mathrm{kg}$ of nitrogen applied. This estimated yield increase is confirmed by data in a summary of DE Geus (op. cit.). For instance, the responses of lowland paddy obtained at the Guttack Institute in India were 11.4 and $19.3 \mathrm{~kg}$ of paddy for each $\mathrm{kg}$ of nitrogen applied on the wet surface, and before planting below the aerobic mudlayer, respectively.

Of course this is an average based on the results of 25 experiments. On some of the fields (figure 3), the uptake-yield curve for nitrogen is not straight and not independent of the phosphate treatment. Here only $30 \mathrm{~kg}$ of paddy was obtained for each $\mathrm{kg}$ of nitrogen taken up from fertilizer and the yield response in case of proper placement should be here only $0.36 \times 30=11 \mathrm{~kg}$ of paddy for each kg of nitrogen applied. Prices in Burma are such, that this return is certainly not paying. The average recovery is used in this calculation, because the results of the single experiments (no repetition) were subject to large random errors. The uptake-yield curve is affected by these errors to a much smaller extent, because the shape of this curve is mainly determined by the percentage content of the minerals in the harvests products.

In figure $2 b$ (quadrant IV) it is read that the recovery of phosphate is about 0.06 . This recovery percentage is not low, but it should be at least two times higher (DE WIT, 1953) if the fertilizer is placed.

In quadrant I it may be seen that the utilization of the phosphate, once taken up is small. Instead of about $150 \mathrm{~kg}$ of paddy for each $\mathrm{kg}$ of phosphate taken up from fertilizer, a value which may be obtained on phosphate deficient soils (compare DE WIT (op. cit.) and the extrapolated part of the uptake yield curve in figure $2 \mathrm{~b}$ and figure 4 ), this value is here only $45 \mathrm{~kg}$ of paddy. So, even in case of placement, the yield response should be only $0.12 \times 45$ $=5.4 \mathrm{~kg}$ of paddy for each $\mathrm{kg}$ of phosphate applied. In Burma this return is again not paying.

However, on a few fields the uptake-yield curve is straight and independent of the nitrogen treatment. For instance, on the field of figure 4 about $140 \mathrm{~kg}$ of paddy is obtained for each $\mathrm{kg}$ of phosphate taken up from fertilizer and the response should be in case of placement about $0.12 \times 140=17 \mathrm{~kg}$ of paddy for each $\mathrm{kg}$ of phosphate applied. This return pays even in Burma.

At last one remark on the interrelations between the effect of phosphate and nitrogen is made. In figure $2 b$ it is shown that, in spite of the increased uptake of phosphate the yield response is low and in figure $2 \mathrm{a}$, where the uptake-yield curve for nitrogen is independent of the phosphate treatment, that this yield response to phosphate is quantitatively accounted for by an increased uptake from the nitrogen initially available in the soil (quadrant IV). This suggests that an increased uptake of phosphate affected the root system in such a way that somewhat more nitrogen was taken up and that this extra nitrogen resulted in a small increase of the yield; in other words: on these nitrogen deficient soils, the phosphate effect seems to be a disguised nitrogen effect.

\section{AKNOWLEDGEMENTS}

The author is indebted to R. S. Koshal and U MaUng Maung Khin of the Department of Agriculture of the Union of Burma for their permission to analyse soil and plant samples 
of their experiments and to U KHIN WIN and T. K. SEN of the Agricultural Research Institute in Rangoon for the analyses and assistance during the interpretation.

\section{LITERATURE CITED}

Reports of the Meetings of the Working Parties on Fertilizers of the International Rice Commission 1952-1955. FAO, Rome.

Geus, J. G. DE: Means of increasing rice production. Centre d'Etude de l'Azote Geneva (1954).

Kosmat, R. S. and MG MG KrIN : A note on the pilot crop cutting experiments and fertilizer experiments on paddy conducted in cultivator's fields in Pegu District: 19541955. Stenciled Report, Dept. of Agr., Burma (1955).

WIT, C. T. DE : A physical theory on placement of fertilizers. Versl. Landb. Onderz. 59.4 (1953).

- - and Krin WIN: The analyses of the results of $25 \mathrm{~N}-\mathrm{P}$ experiments in Pegu District of Lower Burma. Stenciled Report No. 11, Agr. Research Inst., Rangoon, Burma (1955). 